\title{
Cost recovery by Health Canada and drug safety: a time-series analysis
}

\author{
Joel Lexchin MSc MD
}

\section{Abstract}

Background: In 1995, Health Canada started collecting fees from pharmaceutical companies for various drug regulatory activities. This study investigated whether this change in the source of revenue affected the postmarket safety of drugs.

Methods: A list of all new active substances approved in the 5 years before (1990-1994) and after (1995-1999) the introduction of cost recovery was compiled. Drug safety warnings and market withdrawals due to safety reasons were identified from the Health Canada Web site and other sources. Information about total funding for Health Canada's drug regulatory program came from a report by KPMG, a global professional service company providing financial audit, tax and advisory services. Time-series analyses and Kaplan-Meier curves were used to determine whether cost recovery affected postmarket safety.

Results: The introduction of cost recovery made no difference in the proportion of new active substances that received a safety warning, the number of safety warnings per new active substance or the time until the first safety warning or the likelihood that a drug would have a safety problem. Median drug review times decreased significantly after cost recovery was implemented $(p=0.02)$.

Interpretation: The introduction of cost recovery and the associated reduction in review times did not affect the postmarket safety of drugs. Further changes to cost recovery, as are currently being proposed by Health Canada, need to be evaluated for any potential effects on the approval process that might influence decisions that Health Canada makes about the safety and efficacy of new drugs.

I ince January 1995, Health Canada has been collecting fees from pharmaceutical companies under a policy termed cost recovery in return for various regulatory and related activities. These include an annual fee for each product a company markets, fees for reviewing the clinical information that a company files to obtain approval to market a drug, and fees to authorize the company to make, distribute and import drugs. ${ }^{1}$ The goal behind cost recovery is to transfer "some or all of the costs of a government activity from the general taxpayer to those who more directly benefit from or who 'trigger' that special activity." Cost recovery was not meant to supplement parliamentary appropriations to Health Canada but, rather, to replace the $50 \%$ loss of funding that occurred in the early to mid-1990s owing to government restraint policies. ${ }^{1}$

Since the start of the policy, fees have been increased several times, most recently in 2011. Currently, cost recovery supplies about $40 \%$ of the operating budget for the drug regulatory system, ${ }^{2}$ but Health Canada is proposing to raise the amount collected to ultimately cover $90 \%$ of its costs. ${ }^{3}$

Critics of cost recovery have argued that it puts Health Canada in a position of conflict of interest with respect to its decisions about whether to allow a drug on the market. ${ }^{4}$ The effects of conflict of interest might be manifested through less rigorous evaluation of the clinical evidence that companies submit when they apply to market a new drug, resulting in products' having an increased risk of causing harm once they are marketed. The present study was conducted to examine whether there was a difference in the postmarket safety for drugs approved in the 5 years before and 5 years after the introduction of cost recovery. Specifically, I looked at 4 measures of safety: 1) the proportion of new active substances (i.e., molecules never before sold in Canada in any form) that received a safety warning or were withdrawn, 2) the mean number of safety warnings per product, 3 ) the median time to a first safety warning or withdrawal from the market for safety

Competing interests: See the end of the article.

This article has been peer reviewed.

Correspondence to: Joel Lexchin, jlexchin@yorku.ca

CMAJ Open 2018. DOI:10.9778/cmajo.20180146 
reasons (hereafter referred to collectively as safety warning) and 4) whether there is a difference in the likelihood that new drugs (new active substances) would acquire a safety warning in the period before and after cost recovery was initiated. Secondarily, this study looked at the change in drug review times and funding for the drug regulatory system with the implementation of cost recovery.

\section{Methods}

\section{List of new active substances approved}

I compiled a list of all new active substances approved in the 5 -year periods before (1990-1994) and after (1995-1999) cost recovery started. An Access to Information and Privacy request was initially sent to Health Canada requesting a list of all new active substances approved in 1990-1994 inclusive. Health Canada responded that such a request was not necessary to receive this information and supplied the necessary list, drawing from a variety of sources since annual reports were not produced during this period. I generated a list of new active substances approved from 1995 to 1999 from the annual reports of the Therapeutic Products Directorate (small-molecule drugs) and the Biologics and Genetic Therapies Directorate (biologics and vaccines). (Reports can be obtained by contacting the directorates directly at < publications@hc-sc.gc.ca >.) For each new active substance, I abstracted the generic name and date of approval (date of Notice of Compliance). Health Canada noted that the definition of a new active substance had changed over the years, and for this reason it acknowledged that there could be discrepancies between its list and the annual reports for 1995 and onward (Patrick Ridgen, Resource Management and Operations Directorate, Health Canada: personal communication, 2018). In addition, I recorded the median approval times for each year from the annual reports for the period 1995 and onward. Median approval times for 1990-1994 were in the 1995 annual report.

\section{Safety warnings}

Health Canada began systematically posting safety warnings and advisories on its website (www.healthycanadians.gc.ca/ recall-alert-rappel-avis/search-recherche/simple/en/?f_mc $=3$ ) only in July 2000. Before that, safety information was published in 1 of 2 forms: Dear Doctor letters and articles in the Canadian Adverse Drug Reaction Newsletter. I obtained Dear Doctor letters published between Jan. 1, 1990, and the end of publication (Feb. 24, 2000) directly from Health Canada and accessed issues of the Canadian Adverse Drug Reaction Newsletter from my personal collection. I searched the Health Canada Web site for warnings and notices of withdrawals until Apr. 20, 2018. All safety advisories, including those related to drug-drug interactions, were recorded except for those dealing with the withdrawal of a specific batch or lot number owing to manufacturing problems and those issued because of misuse of a drug (e.g., an unapproved use) or medication error (e.g., a warning about remembering to remove a transdermal patch before applying a second one). Safety warnings to the public or to hospitals that duplicated ones issued to health care professionals were also not included. I recorded the date of each safety warning or notice that a drug was removed from the market along the reason for the warning or withdrawal. Dates for safety warnings from Canadian Adverse Drug Reaction Newsletter articles were taken as the first day of the month of the issue of the newsletter. Information about drug withdrawals was supplemented by data from an article about drug withdrawals from 1963 to $2004 .^{5}$

The 1990-1994 group of drugs was on the market for an average of 5 years longer than the 1995-1999 group, and this might have affected the likelihood that a drug would receive a safety warning. From 2013 onward, 5 drugs in the earlier group received a first safety warning, and there were 31 new safety warnings; all these safety warnings were removed from the analysis.

\section{Funding of drug regulatory program}

I calculated estimates of total funding for Health Canada's drug regulatory program in constant 1998-1999 dollars and the proportion of funding that came from cost recovery from a figure in a report by KPMG, a global professional service company providing financial audit, tax and advisory services. ${ }^{1}$ Information on funding for 1990 was not available.

\section{Potential confounders}

Several factors could have affected the likelihood that a drug would receive a safety warning because of possible different safety characteristics, including whether it was a smallmolecule drug or biologic, its therapeutic group and whether it was approved through the standard 300-day review process or the 180-day priority review process. Health Canada annual reports began differentiating between small-molecule drugs and biologics only in 1999, but the list of products approved between 1990 and 1994 that I obtained from Health Canada differentiated biologics from small-molecule drugs. I used the Notice of Compliance database (https://health-products. canada.ca/noc-ac/index-eng.jsp) to determine biologics and small-molecule drugs for 1995-1999. I categorized all drugs into therapeutic groups using the second level of the World Health Organization Anatomic Therapeutic Chemical classification system. ${ }^{6}$ However, the list of new active substances approved in 1990-1994 did not identify which drugs went through a priority review process, so a comparison between the periods before and after cost recovery was possible only for 2 of the 3 possible confounders.

\section{Statistical analysis}

For each year, I calculated the following 4 measures: the proportion of new active substances that eventually acquired a safety warning, the number of safety warnings per new active substance, the median time in years until the first safety warning and the median time in years that a new active substance spent in the drug approval process. I calculated linear time trend lines for the 2 study periods (1990-1994 and 19951999) for each of these measures and compared them using Pearson correlation. In addition, I calculated Kaplan-Meier 
survival curves, i.e., time to event curves, for the period from approval until a first postmarket safety warning or withdrawal for drugs in the entire 1990-1994 and 1995-1999 periods and compared the curves using a log rank (Mantel-Cox) test. Kaplan-Meier analysis accounts for the fact that drugs were on the market for various periods of time and, therefore, some drugs were more likely to have received a postmarket safety warning or been withdrawn by the end of the study period (Apr. 20, 2018). I compared the distribution of new active substances in the different Anatomic Therapeutic Chemical groups and the ratio of biologics to all new active substances approved in the 2 periods using the $\chi^{2}$ test. Calculations were done with Prism version 7.0e for Macintosh (GraphPad Software).

\section{Ethics approval}

No patients were involved and all data were publicly available; therefore, ethics approval was not necessary.

\section{Results}

In 1990-1994, Health Canada approved 166 new active substances, compared to 171 in 1995-1999 (Supplementary Tables A1 and A2, Appendix 1, available at www.cmajopen.ca/ content/6/4/E471/suppl/DC1). In both periods, there was 1 occasion when 3 different formulations of a single new active substance were listed: in 1990-1994, there were 3 cases in which a single new active substance was marketed by 2 different companies, and in 1995-1999, there was 1 similar case. For purposes of this study, in each case, they were counted as only 1 new active substance, i.e., the 3 different formulations of the same new active substance were counted as a single new active substance, and when more than 1 company marketed the same new active substance, it was counted as a single new active substance. Therefore, the analysis is based on 161 unique new active substances for 1990-1994 and 168 unique new active substances for 1995-1999.

These drugs were in a total of 66 different second-level Anatomic Therapeutic Chemical therapeutic groups, 55 in 1990-1994 and 51 in 1995-1999 (Supplementary Table A3, Appendix 1). There was no difference in the distribution of the new active substances into different therapeutic groups in the 2 periods $\left(p=0.1, \chi^{2}\right.$ test). There were 22 biologics (13.7\% of the total) in $1990-1994$ and 23 biologics (13.7\% of the total) in $1995-1999$ ( $p=1.0, \chi^{2}$ test). The lack of any difference in the 2 possible confounders indicates that they did not play a role in any of the results.

A total of 25-42 new active substances were approved in any given year. Total funding for the drug regulatory system was $\$ 60-\$ 70$ million before cost recovery and $\$ 54-\$ 71$ million after cost recovery. Industry funding represented $5.4 \%$ of the total in 1995, rising to $68.2 \%$ in 1998 and then decreasing to $46.0 \%$ in 1999 (Table 1 ).

Figure 1 and Figure 2 show time trends for the 2 study periods in the proportion of new active substances that eventually acquired a safety warning and the number of safety warnings per new active substance per year, respectively. On

\begin{tabular}{|lccc|}
\hline \multicolumn{4}{|c|}{$\begin{array}{l}\text { Table 1: New active substances approved and funding for } \\
\text { Health Canada's drug regulatory system, 1990-1999 }\end{array}$} \\
\hline Year & $\begin{array}{c}\text { No. of unique } \\
\text { new active } \\
\text { substances } \\
\text { approved }\end{array}$ & $\begin{array}{c}\text { Total funding for } \\
\text { drug regulatory } \\
\text { system, } \\
\text { \$ millions }\end{array}$ & $\begin{array}{c}\text { \% of funding } \\
\text { from cost } \\
\text { recovery }\end{array}$ \\
\hline 1990 & 25 & NA & 0 \\
\hline 1991 & 27 & 70 & 0 \\
\hline 1992 & 41 & 60 & 0 \\
\hline 1993 & 34 & 64 & 0 \\
\hline 1994 & 34 & 60 & 5.4 \\
\hline 1995 & 27 & 68 & 7.2 .0 \\
\hline 1996 & 33 & 54 & 45.1 \\
\hline 1997 & 42 & 56 & 68.2 \\
\hline 1998 & 30 & 51 & 46.0 \\
\hline 1999 & 36 & 71 & \\
\hline Note: NA $=$ not available. & & & \\
\hline & & & \\
\hline
\end{tabular}

both measures, there was no difference between the 2 periods $(p=0.4$ and $p=0.9$, respectively, Pearson correlation coefficient). Figure 3 depicts the median time to a first safety warning. Although the median time decreased over the entire period, from 9.4 years in 1990 to 5.6 years in 1999, the lines had the same slope, which indicates that the downward trend seen in the latter period was just a continuation of the decline that had begun in the earlier period ( $p=1.0$, Pearson correlation coefficient). Figure 4 shows the significant decline in the median time that a new active substance spent in the drug approval system once cost recovery was implemented $(p=$ 0.02 , Pearson correlation coefficient.)

Figure 5 shows the Kaplan-Meier survival curves, i.e., the likelihood that a drug would receive a safety warning or be withdrawn from the market, for the 2 study periods. The 2 curves were not significantly different $(p=0.6$, Mantel-Cox test).

\section{Interpretation}

All of the safety measures analyzed in this study - proportion of approved drugs receiving a safety warning, number of safety warnings per product, median time to first safety warning or withdrawal, and likelihood of receiving a safety warning - showed that the introduction of cost recovery by Health Canada did not affect the postmarket safety of drugs.

Drug approval times decreased by about $50 \%$, although overall funding for the drug regulatory system decreased 1 year after the introduction of cost recovery and recovered to previous levels only in 1995 and just barely surpassed the 1991 level in 1999. The change in approval times with the introduction of cost recovery mirrors what happened in the United States, where cost recovery (or user fees, as it is termed) began in 1992 with the passage of the Prescription Drug User Fee Act, which has subsequently been renewed at 5 -year intervals. 


\section{Research}

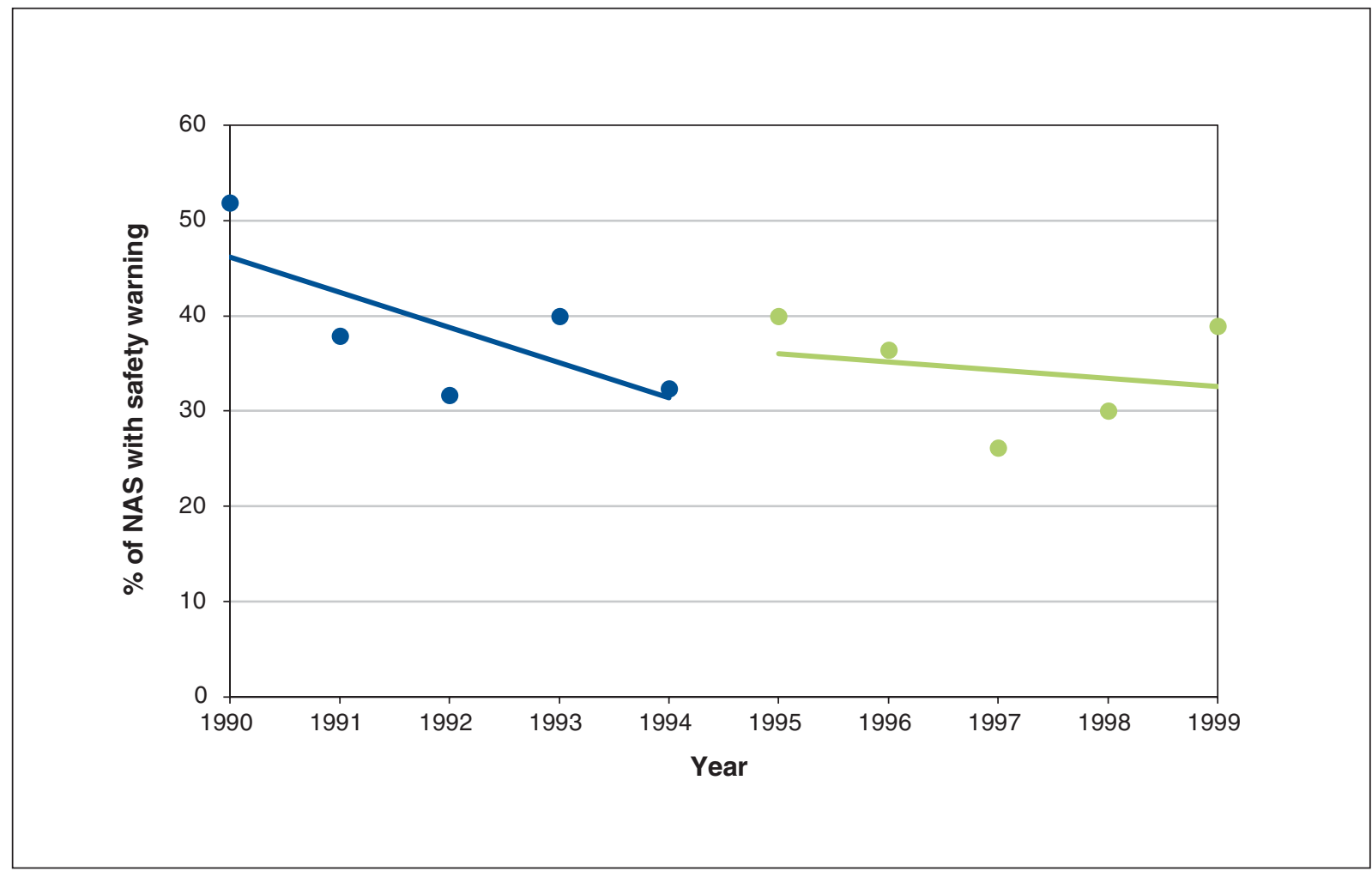

Figure 1: Proportion of new active substances (NAS) that eventually acquired a safety warning before and after the introduction of cost recovery. Difference between the 2 periods not statistically significant ( $p=0.4$, Pearson correlation coefficient).

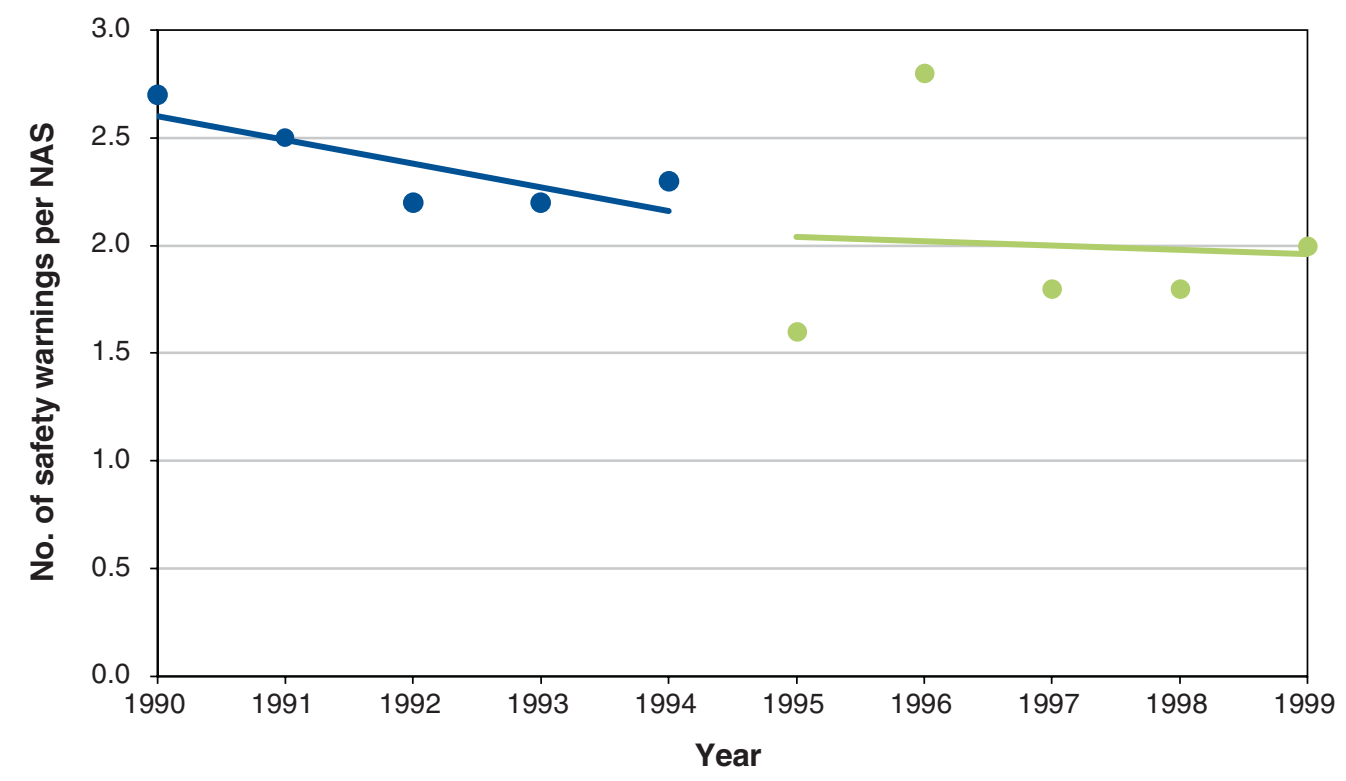

Figure 2: Number of safety warnings per new active substance (NAS) before and after the introduction of cost recovery. Difference between the 2 periods not statistically significant ( $p=0.9$, Pearson correlation coefficient). 


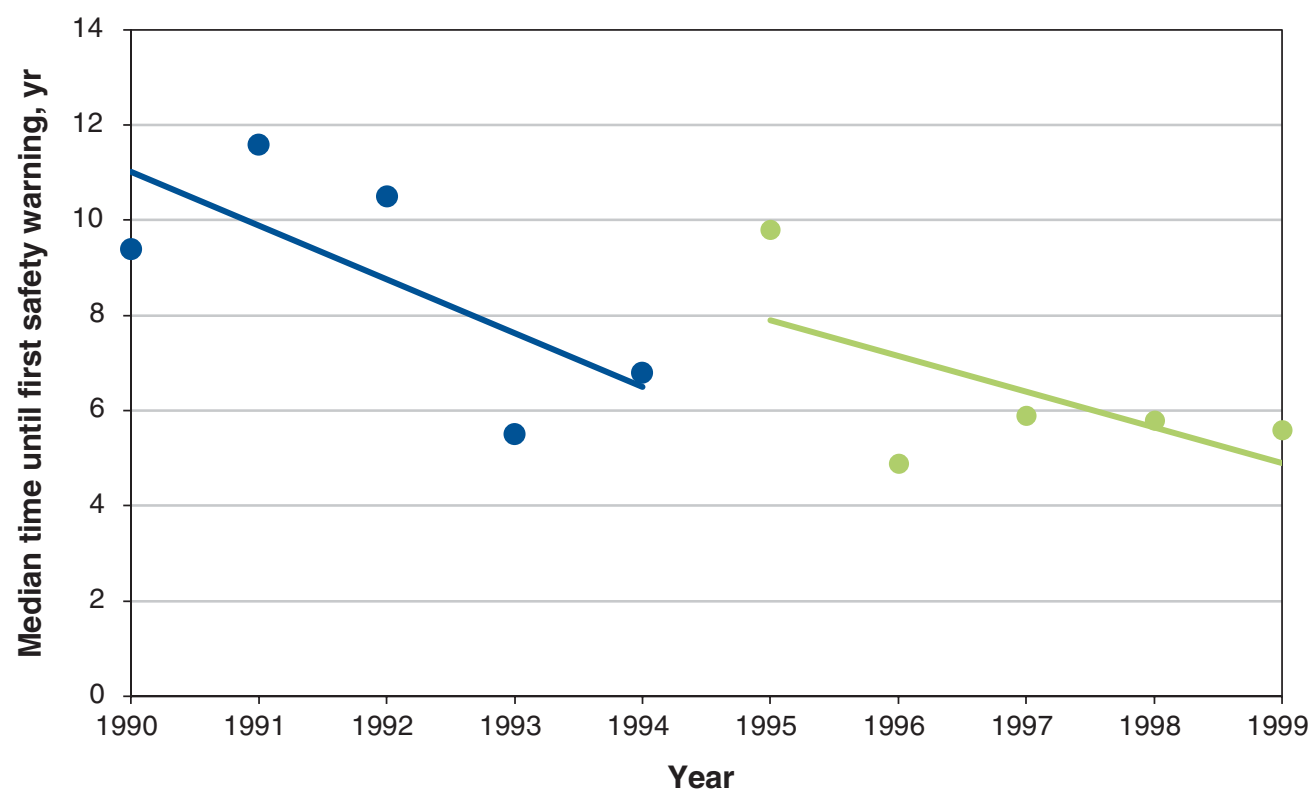

Figure 3: Median time until first safety warning before and after the introduction of cost recovery. Difference between the 2 periods not statistically significant ( $p=1.0$, Pearson correlation coefficient).

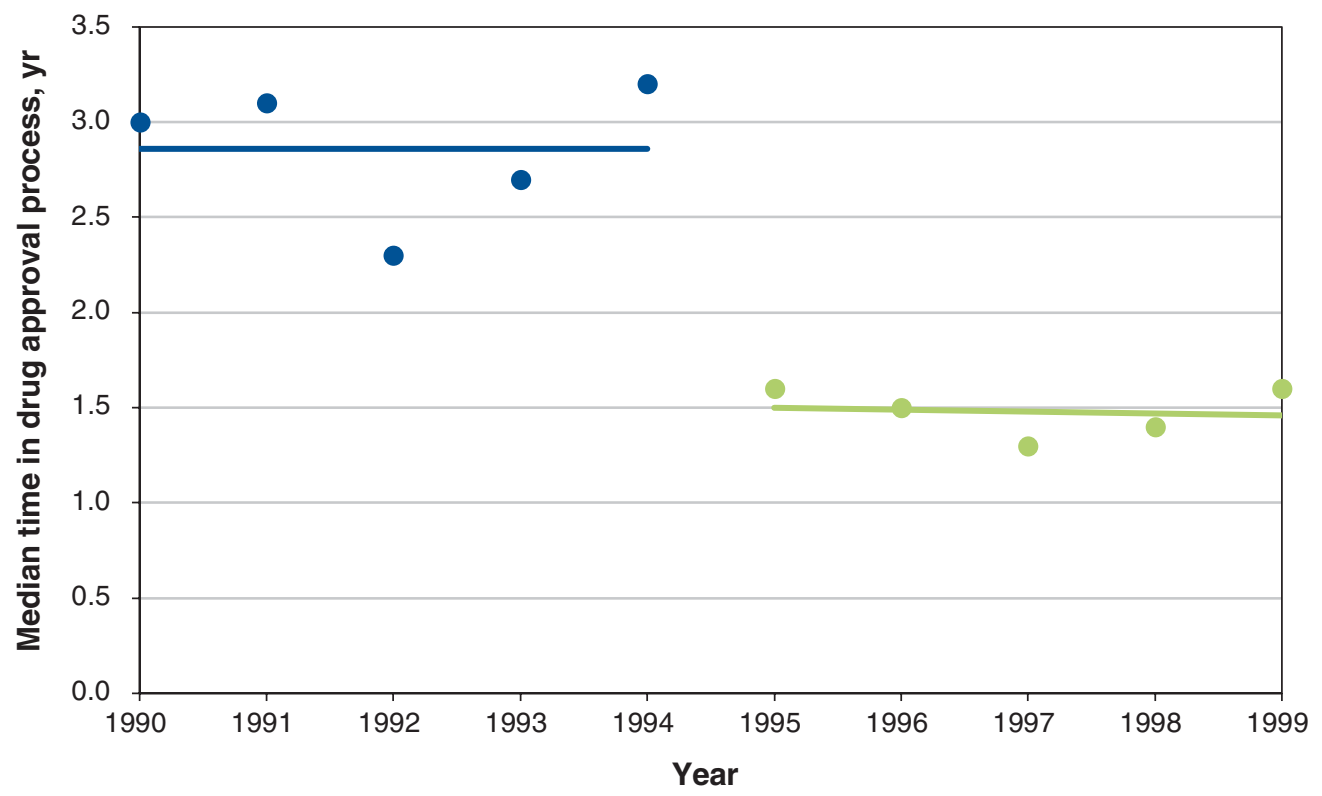

Figure 4: Median time that a new active substance spent in the drug approval process before and after the introduction of cost recovery. Difference between the 2 periods statistically significant $(p=0.02$, Pearson correlation coefficient). 


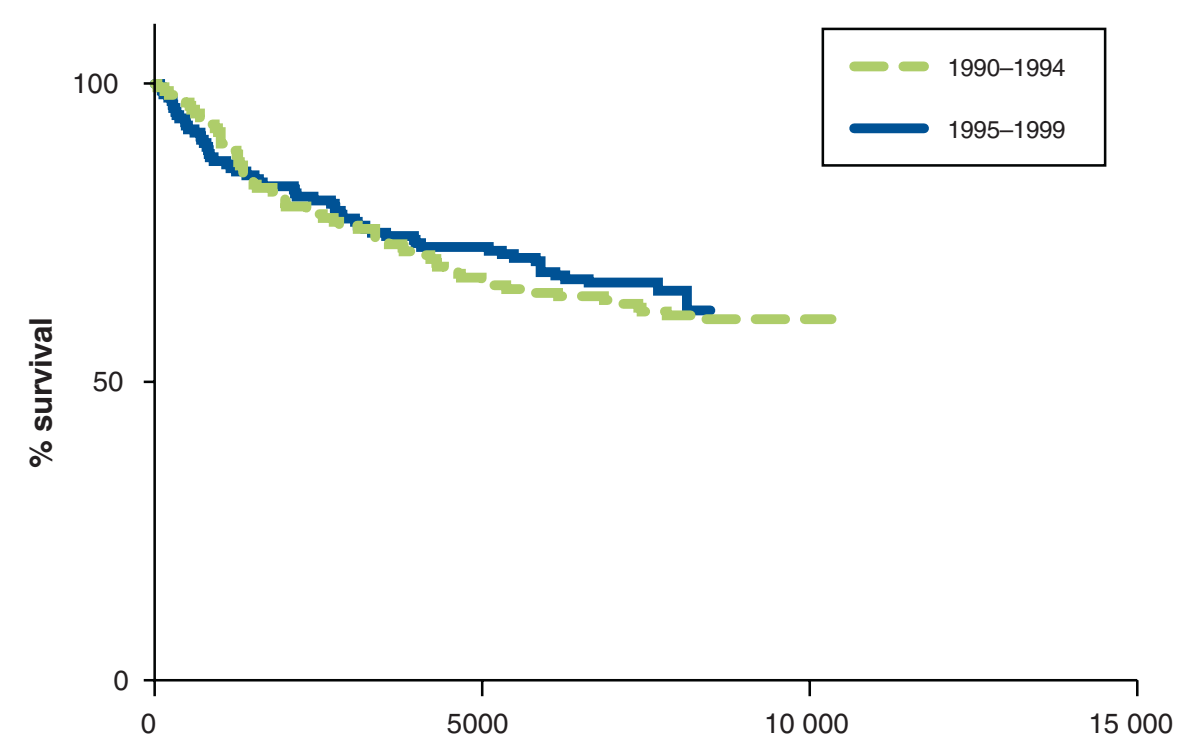

Days from NOC to first safety warning or withdrawal

Figure 5: Kaplan-Meier survival curves showing the likelihood that a drug would receive a safety warning or be withdrawn from the market before and after the introduction of cost recovery. Curves not statistically different $(p=0.6$, Mantel-Cox test). Note: $\mathrm{NOC}=$ Notice of Compliance.

The Prescription Drug User Fee Act led to a decrease in median drug review times, from 33.6 months in 1979-1986 to 16.1 months in 1997-2002. ${ }^{7}$ The difference is that, in the US, review times were mandated under the legislation, whereas in Canada, they were not. Although Health Canada has explicitly denied that there is any relation between review times and user fees, ${ }^{8}$ a 1998 Health Canada document about user fees makes the case that there is with the statement "It was agreed that the fee regulations would be amended to make this link [with review performance] as soon as possible after the government determines the best way to proceed." ${ }^{9}$ Faster approval times mean that drugs reach patients sooner. Although this decrease in approval times did not change postmarket safety, as measured by the metrics used in this study, its effect on the overall quality of the review conducted by Health Canada was not assessed.

Commentators in the US expressed concern about user fees in that country. When user fees came up for reauthorization in 2007, 22 prominent clinicians and former Food and Drug Administration officials opposed their reauthorization and instead called for increased Congressional appropriations to allow the Food and Drug Administration to undertake its responsibilities free from any apparent conflict of interest. ${ }^{10}$ However, the US literature is divided about whether shortened drug review times led to an increase in postmarket safety events, with 4 studies supporting this position ${ }^{11-14}$ and 2 supporting the opposite. ${ }^{15,16}$

There is also disagreement in the literature regarding the consequences of priority (i.e., shorter) reviews versus standard reviews. One Canadian study ${ }^{17}$ and 1 US study ${ }^{18}$ showed an association between shorter review times and more safety warnings. But faster regulatory review by the European Medicines Agency was not associated with a greater likelihood of postmarket safety events, ${ }^{19}$ and a second US study showed that postmarket events were statistically significantly less frequent among drugs with shorter review times. ${ }^{20}$ Factors that may explain the difference in the findings include the time period studied, the use of a before-and-after methodology, ${ }^{11,16}$ using adverse drug events instead of safety advisories, labelling changes and drug withdrawals, ${ }^{13,15}$ the lack of a central repository for Dear Health Care Professional letters, ${ }^{19}$ not considering volume of use, ${ }^{17}$ publication in a non-peer-reviewed journal ${ }^{12}$ and difficulty in determining dates of some safety warnings. ${ }^{14}$

\section{Limitations}

This study used a time-series analysis, a relatively strong methodology, but there are a number of potential limitations. First, the number of people affected by the safety problems in the 2 study periods is unknown, as is the severity of those problems. Second, there were no data on use of the drugs, and a larger prescription volume would likely have led to earlier recognition of safety issues. Because of the lack of a central repository for safety warnings in the period before July 2000, some warnings may have been missed. The changing definition of a new active substance may mean that the characteristics of the products in the 2 periods were not identical. Finally, it was not possible to examine confounding based on the ratio of standard versus priority reviews owing to a lack of data. 


\section{Conclusion}

The introduction of cost recovery was not associated with any changes in postmarket safety, although the speed of the drug approval process increased significantly. Further changes to cost recovery, as are currently being proposed by Health Canada, need to be evaluated for any potential effects on the approval process that might affect decisions that Health Canada makes about the safety and efficacy of new drugs.

\section{References}

1. Report volume 1: review of the Therapeutic Products Programme cost recovery initiative. Ottawa: KPMG Canada; 2000.

2. Standing Senate Committee on Social Affairs, Science and Technology. Evidence. 42nd Parliament, 1st sess, 2017 May 18. Available: https://sencanada.ca/ en/Content/Sen/Committee/421/SOCI/53348-e (accessed 2018 Apr. 24).

3. Fee proposal for drugs and medical devices (for consultation). Ottawa: Health Canada; 2017. Available: https://www.canada.ca/en/health-canada/programs/ consultation-fee-proposal-drugs-medical-devices/drug-medical-device-fee-change -proposal.html (accessed 2018 Oct. 9).

4. Lexchin J. Private profits vs public policy: the pharmaceutical industry and the Canadian state. Toronto: University of Toronto Press; 2016.

5. Lexchin J. Drug withdrawals from the Canadian market for safety reasons, 1963-2004. CMA7 2005;172:765-7.

6. Structure and principles. Oslo (Norway): WHO Collaborating Centre for Drug Statistics Methodology, Norwegian Institute of Public Health; [updated 2018]. Available: www.whocc.no/atc/structure_and_principles/ (accessed 2018 Feb. 20).

7. Berndt ER, Gottschalk A, Philipson T, et al. Industry funding of the FDA: effects of PDUFA on approval times and withdrawal rates. Nat Rev Drug Discov $2005 ; 4: 545-54$.

8. Improving Canada's regulatory process for therapeutic products. Ottawa: Public Policy Forum; 2003. Available: www.policy.ca/policy-directory/Detailed/ Improving-Canada_s-Regulatory-Process-for-Therapeutic-Products-491.html (accessed 2018 Oct. 9).

9. Cost recovery. Ottawa: Health Canada; 1998.

10. Angell M, Avorn J, Bingham E, et al. An open letter to Chairman Edward Kennedy and Senator Mike Enzi, Chairman John Dingell and Representative Joe Barton, Members of the Senate Health, Education, Labor and Pensions Committee, Members of House Energy and Commerce Committee 2007 Mar. 14. Available: https://www.pharmamedtechbi.com/ /media/Images/ Publications/Archive/The\%20Pink\%20Sheet/69/016/00690160007/pdufa_open _letter.pdf (accessed 2018 Apr. 24).

11. Frank C, Himmelstein D, Woolhandler S, et al. Era of faster FDA drug approval has also seen increased black-box warnings and market withdrawals. Health Aff Millwood 2014;33:1453-9.

12. Reaves N. Drug approvals and drug safety: preliminary results. In: Jozefowicz JJ, editor. Proceedings of the Pennsylvania Economic Association 2009 Conference; 2009 June 4-6; West Chester (PA): West Chester University of Pennsylvania; 2009:79-85.
13. Olson MK. The risk we bear: the effects of review speed and industry user fees on new drug safety. 7 Health Econ 2008;27:175-200.

14. Rawson NS. New drug approval times and safety warnings in the United States and Canada, 1992-2011. F Popul Ther Clin Pharmacol 2013;20:e67-81.

15. Grabowski H, Wang Y. Do faster Food and Drug Administration drug reviews adversely affect patient safety? An analysis of the 1992 Prescription Drug User Fee Act. 7 Law Econ 2008;51:377-406.

16. Begosh A, Goldsmith J, Hass E, et al. Black box warnings and drug safety: exam ining the determinants and timing of FDA warning labels. Cambridge (MA): National Bureau of Economic Research; 2006.

17. Lexchin J. New drugs and safety: What happened to new active substances approved in Canada between 1995 and 2010? Arch Intern Med 2012;172: $1680-1$.

18. Mostaghim SR, Gagne J, Kesselheim A. Safety related label changes for new drugs after approval in the US through expedited regulatory pathways: retrospective cohort study. BMF 2017;358:j3837.

19. Zeitoun JD, Lefevre J, Downing N, et al. Regulatory review time and postmarket safety events for novel medicines approved by the EMA between 2001 and 2010: a cross-sectional study. Br 7 Clin Pharmacol 2015;80:716-26.

20. Downing NS, Shah N, Aminawung J, et al. Postmarket safety events among novel therapeutics approved by the US Food and Drug Administration between 2001 and 2010. 7AMA 2017;317:1854-63.

Competing interests: In 2015-2018, Joel Lexchin was a paid consultant on 3 projects: 1 looking at indication-based prescribing (United States Agency for Healthcare Research and Quality), a second to develop principles for conservative diagnosis (Gordon and Betty Moore Foundation) and a third deciding what drugs should be provided free of charge by general practitioners (Government of Canada, Strategy for Patient-Oriented Research in Ontario - the Ontario SPOR SUPPORT Unit and St. Michael's Hospital Foundation). He also received payment for being on a panel that discussed a pharmacare plan for Canada (Canadian Institute, a for-profit organization). He is currently a member of research groups that are receiving money from the Canadian Institutes of Health Research and the Australian National Health and Medical Research Council. He is member of the Foundation Board of Health Action International and the Board of Canadian Doctors for Medicare.

Affiliations: School of Health Policy and Management, York University; University Health Network; and Department of Family and Community Medicine, University of Toronto, Toronto, Ont.

Acknowledgement: The author is grateful to Patrick Ridgen for his assistance in obtaining the list of new active substances approved by Health Canada between 1990 and 1994.

Supplemental information: For reviewer comments and the original submission of this manuscript, please see www.cmajopen.ca/content/6/4/ E471/suppl/DC1. 